NBER WORKING PAPER SERIES

\title{
E-STABILITY VIS-A-VIS DETERMINACY RESULTS FOR A BROAD CLASS OF LINEAR RATIONAL EXPECTATIONS MODELS
}

\author{
Bennett T. McCallum \\ Working Paper 12441 \\ http://www.nber.org/papers/w12441 \\ NATIONAL BUREAU OF ECONOMIC RESEARCH \\ 1050 Massachusetts Avenue \\ Cambridge, MA 02138 \\ August 2006
}

I am indebted to Juan-Carlos Cordoba, George Evans, Christian Jensen, Takushi Kurozumi, and two referees for helpful comments. The views expressed herein are those of the author(s) and do not necessarily reflect the views of the National Bureau of Economic Research.

(C)2006 by Bennett T. McCallum. All rights reserved. Short sections of text, not to exceed two paragraphs, may be quoted without explicit permission provided that full credit, including (C) notice, is given to the source. 
E-Stability vis-a-vis Determinacy Results for a Broad Class of Linear Rational Expectations Models

Bennett T. McCallum

NBER Working Paper No. 12441

August 2006

JEL No. C62, D84, C63, E00

\begin{abstract}
It is argued that learnability/E-stability is a necessary condition for a RE solution to be plausible. A class of linear models considered by Evans and Honkapohja (2001) is shown to include all models of the form used by King and Watson (1998) and Klein (2000), which permits any number of lags, leads, and lags of leads. For this broad class it is shown that, if current-period information is available in the learning process, determinacy is a sufficient condition for E-stability. It is not a necessary condition, however; there exist cases with more than one stable solution in which the solution based on the decreasing-modulus ordering of the system's eigenvalues is E-stable. If in such a case the other stable solution(s) are not E-stable, then the condition of indeterminacy may not be important for practical issues.
\end{abstract}

Bennett T. McCallum

Tepper School of Business, Posner 256

Carnegie Mellon University

Pittsburgh, PA 15213

and NBER

bm05@andrew.cmu.edu 


\section{$\underline{\text { 1. Introduction }}$}

Much recent research in economics, especially in monetary economics, has focused on issues involving analytical indeterminacy - multiplicity of stable rational expectations solutions - often in dynamic general equilibrium models based on optimizing behavior by individual agents. ${ }^{1}$ In this context, the recent appearance of major publications by Evans and Honkapohja $(1999,2001)$ has stimulated new interest in the concept of E-stability, developed by DeCanio (1979), Evans (1985, 1986, 1989), and Evans and Honkapohja (1992). ${ }^{2}$ The reason is that E-stability is very closely linked with least-squares learnability, and the latter is arguably a necessary property for a rational expectations solution to be plausible as an equilibrium for the model at hand. ${ }^{3}$ In their book, Evans and Honkapohja (henceforth, E\&H) provide conditions for E-stability of a class of linear multivariate models, but the class in question might appear to be rather restricted in scope. It is shown below, however, that the E\&H specification is in fact quite broad, in the sense that essentially any model of the class analyzed by King and Watson (1998) or Klein (2000) can be represented in the implied form. It follows that analytical results shown to hold for the E\&H class are actually of quite broad applicability.

In the present paper, consequently, I draw upon results of E\&H $(1999,2001)$ and McCallum (1998) to develop simple proofs of two useful propositions pertaining to this broad class of linear rational expectations (RE) models. The first, Proposition P1, is that

\footnotetext{
${ }^{1}$ In monetary economics such issues include indeterminacy under inflation forecast targeting (Woodford, 1994; Bernanke and Woodford, 1997; King, 2000), deflationary traps (Benhabib, Schmitt-Grohe, and Uribe, 2001), the fiscal theory of the price level (Sims, 1994; Woodford, 1995; Cochrane, 1998;

Kotcherlakota and Phelan, 1999; McCallum, 2001), and the validity of the "Taylor Principle" (Woodford, 2003). For a useful overview of several related points, see Bullard and Mitra (2002).

${ }^{2}$ Evans and Honkapohja (1999) is an extensive survey article in the Taylor-Woodford Handbook of Macroeconomics, whereas their (2001) is a major treatise published by Princeton University Press.

${ }^{3}$ This position is developed on pp. 2-3, while Appendix A briefly reviews relevant concepts.
} 
if a RE solution is determinate (unique dynamically stable), then it has the property of E-stability (and therefore least squares learnability). The second proposition, P2, is that there exist various cases with a multiplicity of stable ${ }^{4}$ solutions in which the one based on the decreasing-modulus ordering of the system's eigenvalues is E-stable. Furthermore, it is a simple matter to determine whether the requisite criteria for E-stability are satisfied.

It should be stated clearly at the outset that all results presented here are based on the assumption that current values of endogenous variables are included in individuals' information sets; if instead only lagged endogenous variables can be observed in the learning process then different E-stability and learnability results would be relevant. Analysis of a few particular problems in monetary economics involving the latter specification has been conducted in a well-known paper by Bullard and Mitra (2002) while recent papers by Adam (2003) and Adam, Evans, and Honkapohja (2006) have emphasized that differing assumptions about information sets relevant for learning can lead to different conclusions.

The position that learnability (and thus E-stability) should be regarded as a necessary condition for the relevance of a RE equilibrium begins with the presumption that individual agents must somehow learn the magnitudes of parameters describing the economy's law of motion from observations generated by the economy; they cannot be endowed with such knowledge by magic. Of course any particular learning scheme might be incorrect in its depiction of actual learning behavior. But in this regard it is

\footnotetext{
${ }^{4}$ Throughout, the unmodified word "stable" will refer to the presence or absence of dynamic stability of the rational expectations solution in question, not the learning process or the meta-time concept of E-stability.

${ }^{5}$ Bullard and Mitra (2002) obtain a result analogous to P1, under the current-information condition, for a particular three-variable model relating to monetary policy, whereas Evans and Guesnerie (2003) present the same result for cases in which $A_{11}$ is nonsingular and Evans and Honkapohja (2003) for cases in which $\mathrm{C}=0$. In none of these papers is broad applicability claimed.
} 
important to note that the LS learning process in question assumes that (i) agents are collecting an ever-increasing number of observations on all relevant variables while (ii) the structure is remaining unchanged. Furthermore, (iii) the agents are estimating the relevant unknown parameters (iv) with an appropriate estimator (v) in a properly specified model. Thus if a proposed RE solution is not learnable by the process in question — the one to which the E\&H results pertain — then it would seem highly implausible that it could prevail in practice.

The paper's outline is as follows. In Section 2, it is demonstrated that the class of models used by E\&H (2001) is broad enough to include the specifications of KingWatson (1998) and Klein (2000). Then Section 3 outlines the basic algebraic relationships upon which following results depend. Section 4 develops relevant conditions for determinacy after which Section 5 demonstrates the validity of Propositions P1 and P2 and illustrates the latter with numerical examples. There is a particular model discussed by E\&H (1999, pp. 488-490; 2001, pp. 174-181) that might appear to constitute a counterexample to P1. Consequently, that (valid) example is discussed in Section 6. Finally, Section 7 provides a brief recapitulation.

\section{Model Specification}

It will be convenient to work throughout with a model of the form

$$
\mathrm{y}_{\mathrm{t}}=\mathrm{A}_{11} \mathrm{E}_{\mathrm{t}} \mathrm{y}_{\mathrm{t}+1}+\mathrm{C} \mathrm{y}_{\mathrm{t}-1}+\mathrm{Du}_{\mathrm{t}},
$$

where $y_{t}$ is a $m \times 1$ vector of endogenous variables, $A_{11}$ and $C$ are $m \times m$ matrices of real

numbers, $D$ is $m \times n$, and $u_{t}$ is a $n \times 1$ vector of exogenous variables generated by a dynamically stable process

(2) $\quad u_{t}=R u_{t-1}+\varepsilon_{t}$, 
with $\varepsilon_{t}$ a white noise vector. It will not be assumed, even initially, that $A_{11}$ is invertible. Accordingly, we are adopting the specification of Section 10.3 of Evans and Honkapohja (2001), for which E-stability conditions are reported on their p. 238. Constant terms can be included in the equations of (1) by specifying one exogenous variable in $u_{t}$ to be a random walk whose innovation has mean zero and variance zero. Then this component, say $\mathrm{u}_{1 \mathrm{t}}$, will satisfy $\mathrm{u}_{1 \mathrm{t}}=\mathrm{u}_{1 \mathrm{t}-1}$ and the constant-term magnitudes will be governed by elements of D.

To show that a very wide variety of linear RE models can be written in form (1)(2), consider the formulation of King and Watson (1998) or Klein (2001), as exposited by McCallum (1998), as follows:

$$
\left[\begin{array}{ll}
A_{11}^{*} & 0 \\
0 & I
\end{array}\right]\left[\begin{array}{l}
E_{t} x_{t+1} \\
k_{t+1}
\end{array}\right]=\left[\begin{array}{ll}
B_{11} & B_{12} \\
B_{21} & B_{22}
\end{array}\right]\left[\begin{array}{l}
x_{t} \\
k_{t}
\end{array}\right]+\left[\begin{array}{l}
G_{1} \\
G_{2}
\end{array}\right]\left[v_{t}\right] .
$$

Here $\mathrm{v}_{\mathrm{t}}$ is an $\mathrm{AR}(1)$ vector of exogenous variables (including shocks) with stable AR

matrix $R$ while $x_{t}$ and $k_{t}$ are $m_{1} \times 1$ and $m_{2} \times 1$ vectors of non-predetermined and predetermined endogenous variables, respectively. We assume without significant loss of generality that $B_{11}$ is invertible ${ }^{6}$ and that $G_{2}=0 .^{7}$ Then we define $y_{t}=\left[x_{t}{ }^{\prime} k_{t}{ }^{\prime} x_{t-1}{ }^{\prime} k_{t-1}{ }^{\prime}\right]^{\prime}$ and write the system in form (1) with $\mathrm{u}_{\mathrm{t}}=\mathrm{v}_{\mathrm{t}}$ and the matrices given as follows:

$$
A_{11}=\left[\begin{array}{lllc}
B_{11}^{-1} A_{11}^{*} & 0 & 0 & -B_{11}^{-1} B_{12} \\
0 & 0 & 0 & 0 \\
0 & 0 & 0 & 0 \\
0 & 0 & 0 & 0
\end{array}\right] \quad C=\left[\begin{array}{llll}
0 & 0 & 0 & 0 \\
B_{21} & B_{22} & 0 & 0 \\
I & 0 & 0 & 0 \\
0 & I & 0 & 0
\end{array}\right] \quad D=\left[\begin{array}{c}
-B_{11}^{-1} G_{1} \\
0 \\
0 \\
0
\end{array}\right]
$$

\footnotetext{
${ }^{6}$ For the system (3) to be cogent, each of the $\mathrm{m}_{1}$ non-predetermined variables must appear in at least one of the $\mathrm{m}_{1}$ equations of the first matrix row. Then the diagonal elements of $\mathrm{B}_{11}$ will all be non-zero and to avoid inconsistencies the rows of $\mathrm{B}_{11}$ must be linearly independent. This implies invertibility.

${ }^{7}$ If it is desired to include a direct effect of $\mathrm{v}_{\mathrm{t}}$ on $\mathrm{k}_{\mathrm{t}+1}$, this can be accomplished by definition of an auxiliary variable (equal to $v_{t-1}$ ) in $x_{t}$ (in which case $v_{t}$ remains in the information set for period $t$ ). Also, auxiliary variables can be used to include expectations of future values of exogenous variables.
} 
This representation is important because it is well known that the system (3) permits, via use of auxiliary variables, any finite number of lags, expectational leads, and lags of expectational leads for the basic endogenous variables. Also, any higher-order AR process for the exogenous variables can be written in AR(1) form. ${ }^{8}$ Thus we have shown that the Evans and Honkapohja (2001) formulation in their Section 10.3 is in fact rather general, although it does not pertain to asymmetric information models.

\section{$\underline{\text { 3. RE Solutions }}$}

Following McCallum $(1983,1998)$, consider solutions to (1)(2) of the form

$$
\mathrm{y}_{\mathrm{t}}=\Omega \mathrm{y}_{\mathrm{t}-1}+\Gamma \mathrm{u}_{\mathrm{t}} .
$$

in which $\Omega$ is required to be real. Then we have that $\mathrm{E}_{\mathrm{t}} \mathrm{y}_{\mathrm{t}+1}=\Omega\left(\Omega \mathrm{y}_{\mathrm{t}-1}+\Gamma \mathrm{u}_{\mathrm{t}}\right)+\Gamma R \mathrm{u}_{\mathrm{t}}$ and straightforward undetermined-coefficient reasoning shows that $\Omega$ and $\Gamma$ must satisfy

$$
\mathrm{A}_{11} \Omega^{2}-\Omega+\mathrm{C}=0
$$

and

$$
\Gamma=\mathrm{A}_{11} \Omega \Gamma+\mathrm{A}_{11} \Gamma \mathrm{R}+\mathrm{D} .
$$

For any given $\Omega$, (7) yields a unique $\Gamma$ generically, ${ }^{9}$ but there are many $\mathrm{m} \times \mathrm{m}$ matrices that solve (6) for $\Omega$. Accordingly, the following analysis centers around (6).

If $\mathrm{A}_{11}$ were invertible, we could express (6) in the first-order form

$$
\left[\begin{array}{l}
\Omega^{2} \\
\Omega
\end{array}\right]=\left[\begin{array}{cc}
\mathrm{A}_{11}^{-1} & -\mathrm{A}_{11}^{-1} \mathrm{C} \\
\mathrm{I} & 0
\end{array}\right]\left[\begin{array}{l}
\Omega \\
\mathrm{I}
\end{array}\right]
$$

and proceed as in the well-known analysis of Blanchard and Khan (1980), which is based on the eigenvalues of the square matrix on the right-hand side of (8). With $A_{11}$ singular,

\footnotetext{
${ }^{8}$ Binder and Pesaran (1995) show that virtually any linear model can be put in form (1), but in doing so admit a more general specification than (2) for the process generating the exogenous variables. ${ }^{9}$ Generically, $I-R^{\prime} \otimes\left[\left(I-A_{11} \Omega\right)^{-1} A_{11}\right]$ will be invertible, permitting solution of $(7)$ for $\operatorname{vec}(\Gamma)$. Invertibility of $\left(I-A_{11} \Omega\right)$ is discussed and assumed below in Section 4.
} 
however, we proceed as follows. In place of (8), we write

$$
\left[\begin{array}{cc}
\mathrm{A}_{11} & 0 \\
0 & \mathrm{I}
\end{array}\right]\left[\begin{array}{l}
\Omega^{2} \\
\Omega
\end{array}\right]=\left[\begin{array}{cc}
\mathrm{I} & -\mathrm{C} \\
\mathrm{I} & 0
\end{array}\right]\left[\begin{array}{c}
\Omega \\
\mathrm{I}
\end{array}\right]
$$

in which the first row reproduces the matrix quadratic (6). Let the $2 \mathrm{~m} \times 2 \mathrm{~m}$ matrices on the left and right sides of (9) be denoted A and B, respectively. Then instead of focusing on the eigenvalues of $\mathrm{A}^{-1} \mathrm{~B}$, which does not exist when $\mathrm{A}_{11}$ is singular, we instead solve for the (generalized) eigenvalues of the matrix pencil $[\mathrm{B}-\lambda \mathrm{A}]$, alternatively termed the (generalized) eigenvalues of B with respect to A (e.g., Uhlig (1999)). Thus instead of diagonalizing $\mathrm{A}^{-1} \mathrm{~B}$, we use the Schur generalized decomposition, which serves the same purpose. Specifically, the Schur generalized decomposition theorem establishes that there exist unitary matrices $\mathrm{Q}$ and $\mathrm{Z}$ such that $\mathrm{QBZ}=\mathrm{T}$ and $\mathrm{QAZ}=\mathrm{S}$ with $\mathrm{T}$ and $\mathrm{S}$ triangular. ${ }^{10}$ Then eigenvalues of the matrix pencil $(\mathrm{B}-\lambda \mathrm{A})$ are defined as $\mathrm{t}_{\mathrm{ii}} / \mathrm{si}_{\mathrm{ii}}$. Some of these eigenvalues may be "infinite," in the sense that some $s_{i i}$ may equal zero. This will be the case, indeed, whenever $\mathrm{A}_{11}$ and therefore $\mathrm{A}$ are of less than full rank since then $\mathrm{S}$ is also singular. All of the foregoing is true for any ordering of the eigenvalues and associated columns of $Z$ (and rows of Q). For the present, let us focus on the arrangement that places the $\mathrm{t}_{\mathrm{ii}} / \mathrm{s}_{\mathrm{ii}}$ in order of decreasing modulus. ${ }^{11}$

To begin the analysis, premultiply (9) by $\mathrm{Q}$. Since $\mathrm{QA}=\mathrm{SH}$ and $\mathrm{QB}=\mathrm{TH}$, where $\mathrm{H} \equiv \mathrm{Z}^{-1}$, the resulting equation can be written as

$$
\left[\begin{array}{ll}
\mathrm{S}_{11} & 0 \\
\mathrm{~S}_{21} & \mathrm{~S}_{22}
\end{array}\right]\left[\begin{array}{ll}
\mathrm{H}_{11} & \mathrm{H}_{12} \\
\mathrm{H}_{21} & \mathrm{H}_{22}
\end{array}\right]\left[\begin{array}{l}
\Omega^{2} \\
\Omega
\end{array}\right]=\left[\begin{array}{ll}
\mathrm{T}_{11} & 0 \\
\mathrm{~T}_{21} & \mathrm{~T}_{22}
\end{array}\right]\left[\begin{array}{ll}
\mathrm{H}_{11} & \mathrm{H}_{12} \\
\mathrm{H}_{21} & \mathrm{H}_{22}
\end{array}\right]\left[\begin{array}{c}
\Omega \\
\mathrm{I}
\end{array}\right] \text {. }
$$

\footnotetext{
${ }^{10}$ Provided only that there exists some $\lambda$ for which $\operatorname{det}[\mathrm{B}-\lambda \mathrm{A}] \neq 0$. See Klein (2000) or Golub and Van Loan (1996).

${ }^{11}$ The discussion proceeds as if none of the $t_{\mathrm{ii}} / \mathrm{s}_{\mathrm{ii}}$ equals 1.0 exactly. If one does, the model can be adjusted, by multiplying some relevant coefficient by (e.g.) 0.9999 .
} 
The first row of (10) reduces to

$$
\mathrm{S}_{11}\left(\mathrm{H}_{11} \Omega+\mathrm{H}_{12}\right) \Omega=\mathrm{T}_{11}\left(\mathrm{H}_{11} \Omega+\mathrm{H}_{12}\right)
$$

Then if $H_{11}$ is invertible the latter can be used to solve for $\Omega$ as

$$
\Omega=-\mathrm{H}_{11}{ }^{-1} \mathrm{H}_{12}=-\mathrm{H}_{11}{ }^{-1}\left(-\mathrm{H}_{11} \mathrm{Z}_{12} \mathrm{Z}_{22}{ }^{-1}\right)=\mathrm{Z}_{12} \mathrm{Z}_{22}{ }^{-1},
$$

where the second equality comes from the upper right-hand submatrix of the identity $\mathrm{HZ}=\mathrm{I}$, provided that $\mathrm{H}_{11}$ is invertible, which we assume without significant loss of generality. ${ }^{12} 13$

As mentioned above, there are many solutions $\Omega$ to (6). These correspond to different arrangements of the eigenvalues, which result in different groupings of the columns of $\mathrm{Z}$ and therefore different compositions of the submatrices $\mathrm{Z}_{12}$ and $\mathrm{Z}_{22}$. Here, with the eigenvalues $t_{\mathrm{ii}} / \mathrm{s}_{\mathrm{ii}}$ arranged in order of decreasing modulus, the diagonal elements of $\mathrm{S}_{22}$ will all be non-zero provided that $\mathrm{S}$ has at least $\mathrm{m}$ non-zero eigenvalues, which we assume to be the case. ${ }^{14}$ For any solution under consideration to be dynamically stable, the eigenvalues of $\Omega$ must of course be smaller than 1.0 in modulus. To evaluate them in terms of the ratios $t_{i i} / s_{i i}$, note that with $\Omega$ given by (12), the second row of (10) becomes

$$
\mathrm{S}_{22}\left(\mathrm{H}_{21} \Omega+\mathrm{H}_{22}\right) \Omega=\mathrm{T}_{22}\left(\mathrm{H}_{21} \Omega+\mathrm{H}_{22}\right)
$$

or

$$
\mathrm{S}_{22}\left(\mathrm{H}_{22}-\mathrm{H}_{21} \mathrm{H}_{11}{ }^{-1} \mathrm{H}_{12}\right) \Omega=\mathrm{T}_{22}\left(\mathrm{H}_{22}-\mathrm{H}_{21} \mathrm{H}_{11}{ }^{-1} \mathrm{H}_{12}\right)
$$

The latter, by virtue of the lower right-hand submatrix of $\mathrm{HZ}=\mathrm{I}$, is equivalent to

$$
\mathrm{S}_{22} \mathrm{Z}_{22}{ }^{-1} \Omega=\mathrm{T}_{22} \mathrm{Z}_{22}{ }^{-1}
$$

\footnotetext{
12 This invertibility condition, also required by King and Watson (1998) and Klein (2000), obtains except for degenerate special cases of (1) that can be solved by simpler methods than considered here. Note that the invertibility of $\mathrm{H}_{11}$ implies the invertibility of $\mathrm{Z}_{22}$, given that $\mathrm{H}$ and $\mathrm{Z}$ are unitary.

${ }^{13}$ Note that it is not being claimed that all solutions are of the form (12).

${ }^{14}$ From its structure it is obvious that $\mathrm{A}$ has at least $\mathrm{m}$ nonzero eigenvalues so, since $\mathrm{Q}$ and $\mathrm{Z}$ are nonsingular, $\mathrm{S}$ must have rank of at least $\mathrm{m}$. This necessary condition is not sufficient for $\mathrm{S}$ to have at least $\mathrm{m}$ nonzero eigenvalues, however; hence the assumption.
} 
Therefore we have the result

$$
\Omega=\mathrm{Z}_{22} \mathrm{~S}_{22}{ }^{-1} \mathrm{~T}_{22} \mathrm{Z}_{22}{ }^{-1}
$$

so $\Omega$ has the same eigenvalues as $\mathrm{S}_{22}{ }^{-1} \mathrm{~T}_{22}$. The latter is triangular, moreover, so the relevant eigenvalues are the $\mathrm{m}$ smallest of the $2 \mathrm{~m}$ ratios $\mathrm{t}_{\mathrm{ii}} / \mathrm{s}_{\mathrm{ii}}$ (given the decreasingmodulus ordering). For dynamic stability, the modulus of each of these ratios must then be less than 1. [In many cases, some of the m smallest moduli will equal zero.]

\section{Determinacy}

Let us henceforth refer to the solution under the decreasing-modulus ordering as the MOD solution. Now suppose that the MOD solution is stable. For it to be the only stable solution, there must be no other arrangement of the $\mathrm{t}_{\mathrm{ii}} / \mathrm{s}_{\mathrm{ii}}$ that would result in a $\Omega$ matrix with all eigenvalues smaller in modulus than 1.0. Thus each of the $t_{\mathrm{ii}} / \mathrm{s}_{\mathrm{ii}}$ for $\mathrm{i}=1, \ldots, \mathrm{m}$ must have modulus greater than 1.0 , some perhaps infinite. Is there some $\mathrm{m} \times \mathrm{m}$ matrix whose eigenvalues relate cleanly to these ratios? Yes, it is the matrix $\mathrm{F} \equiv\left(\mathrm{I}-\mathrm{A}_{11} \Omega\right)^{-1} \mathrm{~A}_{11}$, which appears frequently in the analysis of Binder and Pesaran $(1995,1997) .{ }^{15}$ Regarding this F matrix, we now wish to show that, for any ordering such that $\mathrm{H}_{11}$ is invertible, including the MOD ordering, we have the equality

$$
\mathrm{H}_{11} \mathrm{~F} \mathrm{H}_{11}^{-1}=\mathrm{T}_{11}^{-1} \mathrm{~S}_{11},
$$

which implies that $\mathrm{F}$ has the same eigenvalues as $\mathrm{T}_{11}{ }^{-1} \mathrm{~S}_{11}$. In other words, we shall show that the eigenvalues of $\mathrm{F}$ are the same, for any given arrangement of the system's eigenvalues, as the inverses of the values of $t_{\mathrm{ii}} / \mathrm{sii}_{\mathrm{ii}}$ for $\mathrm{i}=1, \ldots, \mathrm{m}$. For this proof, note first that the upper left-hand submatrix of $\mathrm{QA}=\mathrm{SH}$ is $\mathrm{Q}_{11} \mathrm{~A}_{11}=\mathrm{S}_{11} \mathrm{H}_{11}$ so we have ${ }^{16}$

$$
\mathrm{Q}_{11} \mathrm{~A}_{11} \mathrm{H}_{11}^{-1}=\mathrm{S}_{11} \text {. }
$$

\footnotetext{
${ }^{15}$ Invertibility of $\left[\mathrm{I}-\mathrm{A}_{11} \Omega\right]$ and $\mathrm{T}_{11}$ will be discussed shortly.

${ }^{16}$ Recall that $\mathrm{H}_{11}$ is required to be invertible.
} 
Now postmultiply by $\mathrm{H}_{12}$, and recall that $\Omega=-\mathrm{H}_{11}{ }^{-1} \mathrm{H}_{12}$, to obtain

$$
-\mathrm{Q}_{11} \mathrm{~A}_{11} \Omega=\mathrm{S}_{11} \mathrm{H}_{12}=\mathrm{Q}_{12},
$$

where we use the upper right submatrix of $\mathrm{QA}=\mathrm{SH}$. Then since $\mathrm{Q}_{11}+\mathrm{Q}_{12}=\mathrm{T}_{11} \mathrm{H}_{11}$ (from the upper right submatrix of $\mathrm{QB}=\mathrm{TH}$ ), we obtain $-\mathrm{Q}_{11} \mathrm{~A}_{11} \Omega=\mathrm{T}_{11} \mathrm{H}_{11}-\mathrm{Q}_{11}$ so it follows that

$$
\mathrm{Q}_{11}\left[\mathrm{I}-\mathrm{A}_{11} \Omega\right]=\mathrm{T}_{11} \mathrm{H}_{11}
$$

Thus we have

$$
\mathrm{Q}_{11}=\mathrm{T}_{11} \mathrm{H}_{11}\left[\mathrm{I}-\mathrm{A}_{11} \Omega\right]^{-1}
$$

provided that $\left[\mathrm{I}-\mathrm{A}_{11} \Omega\right]$ is invertible.

With respect to that invertibility, the analyses of Evans and Honkapohja (2001), Binder and Pesaran $(1995,1997)$, and others proceed under the presumption that $\left[\mathrm{I}-\mathrm{A}_{11} \Omega\right]$ is nonsingular, but without any explicit justification. Binder and Pesaran (1997, fn. 4) observe that invertibility of $\left[\mathrm{I}-\mathrm{A}_{11} \Omega\right]$ does not require the invertibility of $\mathrm{A}_{11}$ and state that they have found no cases of a singular $\left[\mathrm{I}-\mathrm{A}_{11} \Omega\right]$ matrix in any well specified model. But can one develop any general result? In that regard, note from (20) that the rank of $\left[\mathrm{I}-\mathrm{A}_{11} \Omega\right]$ must be $\mathrm{m}$ if the rank of $\mathrm{T}_{11} \mathrm{H}_{11}$ is $\mathrm{m}$, since $\operatorname{rank}\left(\mathrm{Q}_{11}\left[\mathrm{I}-\mathrm{A}_{11} \Omega\right]\right) \leq$ $\min \left[\operatorname{rank}\left(\mathrm{Q}_{11}\right), \operatorname{rank}\left(\left[\mathrm{I}-\mathrm{A}_{11} \Omega\right]\right)\right]$. Also, the same argument can be made in the opposite direction so the nonsingularity of $\mathrm{T}_{11}$ and $\left[\mathrm{I}-\mathrm{A}_{11} \Omega\right]$ go hand in hand. I have not been able to develop a general proof of nonsingularity for $\mathrm{I}-\mathrm{A}_{11} \Omega$, but it seems clear that if $\mathrm{A}_{11} \Omega$ were by chance to have some eigenvalue exactly equal to 1.0 , that condition could be eliminated by making some arbitrarily small adjustment to elements of $\mathrm{A}_{11}$ or $\mathrm{C}$. For practical purposes, then, there would seem to be no significant loss of generality from adoption of the usual invertibility assumption. 
Consequently, we can substitute (21) into (18) and premultiply by $\mathrm{T}_{11}{ }^{-1}$ to obtain

$$
\mathrm{H}_{11}\left[\mathrm{I}-\mathrm{A}_{11} \Omega\right]^{-1} \mathrm{~A}_{11} \mathrm{H}_{11}{ }^{-1}=\mathrm{T}_{11}{ }^{-1} \mathrm{~S}_{11} \text {. }
$$

Therefore, $F=\left[I-A_{11} \Omega\right]^{-1} A_{11}$ has the same eigenvalues as $T_{11}{ }^{-1} S_{11}$. Under the MOD ordering these are the inverses of the first (largest) $m$ of the eigenvalues of the system's matrix pencil, as we set out to show. Accordingly, for solution (12) to be the only stable solution, all the eigenvalues of the corresponding F must be smaller than 1.0 in modulus. This result, stated in different ways, is well known from Binder and Pesaran (1995), King and Watson (1998), and Klein (2000), and is an important generalization of one result of Blanchard and Khan (1980) for a model with nonsingular $\mathrm{A}_{11}$.

To this point we have established notation for models of form (1) and have shown that the existence of a unique stable solution requires that all eigenvalues of the defined $\Omega$ matrix and the corresponding $\mathrm{F}$ must be less than 1.0 in modulus. It will be convenient to express that condition as follows: all $\left|\lambda_{\Omega}\right|<1$ and all $\left|\lambda_{\mathrm{F}}\right|<1$.

\section{E-Stability}

For the model specification given in (1)(2) above, Evans and Honkapohja (2001, p. 238) present necessary and sufficient conditions for E-stability (with our information assumption) of any specified solution. In terms of our notation, these conditions are that the eigenvalues of the three following matrices all have real parts less than $1.0:{ }^{17}$

(23a) $\quad \mathrm{F} \equiv\left(\mathrm{I}-\mathrm{A}_{11} \Omega\right)^{-1} \mathrm{~A}_{11}$

(23b) $\quad\left[\left(\mathrm{I}-\mathrm{A}_{11} \Omega\right)^{-1} \mathrm{C}\right]^{\prime} \otimes \mathrm{F}$

(23c) $\quad R^{\prime} \otimes F$.

\footnotetext{
${ }^{17}$ The notation here is related to that of Evans and Honkapohja (2001) as follows: $A_{11}=\beta, C=\delta, D=\kappa, R$ $=\varphi, \Omega=\mathrm{b}$. With our treatment of constant terms, (23a) is a special case of (23c).
} 
From equation (6) it follows readily that $\left(\mathrm{I}-\mathrm{A}_{11} \Omega\right)^{-1} \mathrm{C}=\Omega$. Therefore, matrix (23b) can be written as $\Omega^{\prime} \otimes$ F. Furthermore, it is a standard result (Magnus and Neudecker, 1988, p. 28) that the eigenvalues of a Kronecker product are the products of the eigenvalues of the relevant matrices (e.g., the eigenvalues of $\Omega^{\prime} \otimes F$ are the products $\lambda_{\Omega} \lambda_{F}$ ).

It is therefore immediately apparent that any unique stable solution, since it requires that all $\left|\lambda_{\Omega}\right|<1$ and all $\left|\lambda_{\mathrm{F}}\right|<1$, implies that conditions (23a) and (23b) hold. Also, since $\left|\lambda_{\mathrm{F}}\right|<1$, condition (23c) holds provided that all $\left|\lambda_{\mathrm{R}}\right| \leq 1$, which we have assumed by specifying that (2) is dynamically stable. Therefore we have a proof of the following proposition:

(P1) Consider solutions of form (5) to models of form (1)(2) with $2 \mathrm{~m} \times 2 \mathrm{~m}$ matrices A and B defined in equation (9). Assume, as in King and Watson (1998) and Klein (2000), that there exists some $\lambda$ for which $\operatorname{det}[\mathrm{B}-\lambda \mathrm{A}] \neq 0$ and that $\mathrm{H}_{11}$ defined in (10) is invertible. Also, assume that that $\mathrm{S}$ has at least $\mathrm{m}$ non-zero eigenvalues and that $\left[\mathrm{I}-\mathrm{A}_{11} \Omega\right]$ is invertible. Then if there exists a determinate solution, it will have the property of E-stability.

This result is of special significance since Evans and Honkapohja (2001, p. 238) show that E-stability plus dynamic stability for models of form (1)(2) together imply leastsquares learnability in real time. ${ }^{18}$

Now let us consider cases with multiple stable solutions of form (12), implying that some $\left|\lambda_{\mathrm{F}}\right|>1$ for whatever eigenvalue arrangement-i.e., whatever particular RE solution - is specified. We focus attention on the MOD solution, with the eigenvalues

\footnotetext{
${ }^{18}$ George Evans has mentioned to me that the univariate model $\mathrm{y}_{\mathrm{t}}=\mu+\mathrm{aE}_{\mathrm{t}-1} \mathrm{y}_{\mathrm{t}}+\mathrm{u}_{\mathrm{t}}$, with $\mathrm{u}_{\mathrm{t}}$ white noise, is determinate with solution $y_{t}=\mu(1-a)^{-1}+u_{t}$ for all a but is E-stable only for $a<1$. It will be shown in Section 6 that, despite appearances, this is not a counterexample to proposition P1.
} 
arranged in order of decreasing modulus. If some $\lambda_{\mathrm{F}}$ has real part greater than 1 , then by (23a) E-stability cannot obtain. But if all eigenvalues for which $\left|\lambda_{F}\right|>1$ are real and negative (i.e., $\lambda_{\mathrm{F}}<-1$ ), or are complex with real parts less than 1 , then the condition pertaining to (23a) would be satisfied. Furthermore, with the MOD ordering it is the case that all $\left|\lambda_{\Omega}\right|<1 /\left|\lambda_{\mathrm{F}}\right|$ so all $\left|\lambda_{\Omega}\right|\left|\lambda_{\mathrm{F}}\right|<1$. But $\left|\lambda_{\Omega}\right|\left|\lambda_{\mathrm{F}}\right|=\left|\lambda_{\Omega} \lambda_{\mathrm{F}}\right| \geq \operatorname{Re}\left(\lambda_{\Omega} \lambda_{\mathrm{F}}\right)$ so (23b) is invariably satisfied. Thus in these cases the MOD solution will be E-stable unless there is some eigenvalue of $R$ that is such that the real part of some $\lambda_{R} \lambda_{F}$ product is greater than 1 . In the case of real values, that would require an eigenvalue of $\mathrm{R}$ that is negative and is fairly large. Accordingly, it is clear that there is a substantial range of cases for which the MOD solution is E-stable; this is our second proposition:

(P2) Consider the model of (P1) with matrices $\Omega$ and F, as defined in (12) and (23) for the MOD ordering of the generalized eigenvalues of the matrix pencil [B $-\lambda \mathrm{A}]$, having eigenvalues $\lambda_{\Omega}$ and $\lambda_{\mathrm{F}}$. Then there exist non-empty open sets of parameter values for which some $\lambda_{F}<-1$, so indeterminacy prevails, but for which conditions (23) are satisfied so the MOD solution is E-stable. ${ }^{19}$ There seems to be no further general result of obvious usefulness, but in any practical application, it is a simple matter to determine whether the relevant conditions obtain. This can be explained as follows.

Suppose that it has been found, in a practical application, that the model at hand is one in which there is more than one stable solution. For simplicity, let us assume that there are two stable solutions. Let $\lambda_{\mathrm{i}}=\mathrm{t}_{\mathrm{ii}} / \mathrm{s}_{\mathrm{ii}}$ be the ith system eigenvalue, with the one

\footnotetext{
${ }^{19}$ Examples are provided, for the univariate model $\mathrm{y}_{\mathrm{t}}=\alpha+\mathrm{aE}_{\mathrm{t}} \mathrm{y}_{\mathrm{t}+1}+\mathrm{cy}_{\mathrm{t}-1}+\mathrm{u}_{\mathrm{t}}$, by region II of the figure on p. 203 of $E \& H$ (2001). There the parameters satisfy $a+c<-1, a<-0.5, c>-0.5$, and ac $<0.25$. Also see the examples that follow below in this section.
} 
with largest modulus listed first, as $\lambda_{1}$. Then it is the case that $\lambda_{\mathrm{m}}, \lambda_{\mathrm{m}+1}, \ldots, \lambda_{2 \mathrm{~m}}$ all have moduli smaller than 1. Our discussion focuses on $\lambda_{m}$ and $\lambda_{m+1}$. For E-stability it is necessary according to (23a) and (23b) that $\operatorname{Re}\left(1 / \lambda_{\mathrm{m}}\right)<1$ and that all $\operatorname{Re}\left(\lambda_{\Omega} / \lambda_{\mathrm{m}}\right)<1$. To observe whether these conditions obtain, all that is required is to have the computational program being used display the system eigenvalues, $\lambda_{1}, \ldots, \lambda_{2 m}$, which can then be multiplied and their values inspected. ${ }^{20}$ Also necessary for E-stability is that all the products $\lambda_{R}\left(1 / \lambda_{m}\right)$ must have real parts smaller than 1 .

From this discussion it follows that there cases exist in which there is more than one stable solution but with the MOD solution being E-stable and the other stable solution(s) being E-unstable (and thus unlearnable). Then our argument, that learnability is a necessary condition for a RE equilibrium to be plausible, would suggest that despite indeterminacy there is only one plausible contender for the economically relevant solution. In such cases, accordingly, indeterminacy would not necessarily imply any problem for real-world applications. $^{21}$

To illustrate the existence of various possibilities, consider the univariate model

$$
x_{t}=a_{1} E_{t} x_{t+1}+a_{2} E_{t} x_{t+2}+c x_{t-1}+u_{t}
$$

with $u_{t}$ being white noise. ${ }^{22}$ To put this into the format of equation (1), define a second endogenous variable $\mathrm{q}_{t}$ equal to $\mathrm{E}_{t} \mathrm{x}_{\mathrm{t}+1}$ so that $\mathrm{y}_{\mathrm{t}}=\left[\begin{array}{ll}\mathrm{x}_{\mathrm{t}} & \mathrm{q}_{t}\end{array}\right]^{\prime}$ and then consider (1) with

\footnotetext{
${ }^{20}$ Since some of the eigenvalues will in many models be "infinite" in principle, it is typically necessary to have the values expressed in scientific notation. For computations, model form (3) will usually be used, rather than (1), but the eigenvalues that are non-zero and finite will be the same.

${ }^{21}$ This point is of importance for deciding whether indeterminacy of an analytical solution is of policy relevance. It should be emphasized, however, that it is not being claimed that the MOD solution is always E-stable or that there are no cases in which two or more solutions are both stable and E-stable. Also, no claim is being made with respect to possible sunspot solutions such as those discussed in Chapter 12 of E\&H (2001) and several recent contributions; only solutions of form (5) are being considered.

${ }^{22}$ This example was usefully suggested by a referee.
} 


$$
\mathrm{A}_{11}=\left[\begin{array}{ll}
\mathrm{a}_{1} & \mathrm{a}_{2} \\
1 & 0
\end{array}\right] \quad \mathrm{C}=\left[\begin{array}{ll}
\mathrm{c} & 0 \\
0 & 0
\end{array}\right] \quad \mathrm{D}=\left[\begin{array}{l}
1 \\
0
\end{array}\right]
$$

First suppose that $\mathrm{a}_{1}=-1.5, \mathrm{a}_{2}=-0.2$, and $\mathrm{c}=0.4$. This specification gives rise to the system eigenvalues $-6.71,-1.07,0.279$, and 0.000 so there is a unique determinate and learnable solution. Change $\mathrm{a}_{2}$ to 0.05 , however, and the eigenvalues become 30.64 , $-0.926,0.282$, and 0.000 . In this case there are two stable solutions, but only the MOD solution is E-stable and learnable since for the other stable solution one $\lambda_{\mathrm{F}}$ equals $1 / 0.282$ $>1$ thereby violating requirement (23a). Next change $\mathrm{c}$ to -0.1 , however, and the eigenvalues become $30.65,-0.532,-0.123$, and 0.000 , in which case only the MOD solution is learnable because the other fails condition (23b).. Continuing in this way it can be found that if we have $\mathrm{a}_{1}=1.5, \mathrm{a}_{2}=-0.05$, and $\mathrm{c}=0.1$ then the eigenvalues are $29.3,0.557,0.122$, and 0.000 so there are two stable solutions but neither is learnable whereas if $\mathrm{c}$ is changed to -0.1 the eigenvalues are $29.3,0.773,-0.0883$, and 0.000 so there are two stable solutions but only the non-MOD solution is learnable.

Some readers may wonder about the relationship between the MOD solution and the solution termed MSV, for “minimum state variable," by McCallum (1983, 1998, 1999). These two concepts are defined differently, the latter being the solution of form (5) that results when the eigenvalue ordering in equations (10)-(12) is such that each of the final $\mathrm{m}$ eigenvalues approaches zero as the elements of the $\mathrm{C}$ matrix approach zeros. ${ }^{23}$ (The precise condition in this statement is that $\mathrm{C}$ is replaced in the model by $\alpha \mathrm{C}$ and $\alpha$ is taken to approach 0.) In many applications the MOD and MSV solutions will coincide, as noted by McCallum (1998, p. 146), but there are exceptions (when $m>1$ ), as

\footnotetext{
${ }^{23}$ Thus the MSV solution as defined by McCallum $(1983,1999)$ is a unique special case of those solutions termed "MSV" by Evans and Honkapohja (2001). This is noted by E\&H (2001, pp. 194, 212).
} 
conjectured by Uhlig (1999, p. 46). ${ }^{24}$

\section{A Special Case}

At first glance, one might doubt the validity of proposition P1 on the basis of the demonstration by E\&H (2001, pp. 174-181; 1999, pp. 488-492) that the univariate model

$$
x_{t}=\mu+a E_{t-1} x_{t}+w_{t},
$$

with $\mathrm{w}_{t}$ white noise, is determinate for all values of a (assuming $\mathrm{a} \neq 1$ ) but is E-stable only for a $<1$. This result is not a counter-example to our proposition $\mathrm{P} 1$, however, for the $\mathrm{E} \& \mathrm{H}$ analysis presumes that current values of $\mathrm{x}_{\mathrm{t}}$ are not included in agents' information sets for expectation formation in $\mathrm{t}$ whereas our proposition pertains to models in which such $\mathrm{x}_{\mathrm{t}}$ values are included. To show explicitly that our proposition does refer to this case, we write (24) as follows:

$$
\left[\begin{array}{l}
\mathrm{x}_{\mathrm{t}} \\
\mathrm{k}_{\mathrm{t}}
\end{array}\right]=\left[\begin{array}{ll}
0 & 0 \\
1 & 0
\end{array}\right]\left[\begin{array}{l}
\mathrm{E}_{\mathrm{t}} \mathrm{x}_{\mathrm{t}+1} \\
\mathrm{E}_{\mathrm{t}} \mathrm{k}_{\mathrm{t}+1}
\end{array}\right]+\left[\begin{array}{ll}
0 & \mathrm{a} \\
0 & 0
\end{array}\right]\left[\begin{array}{l}
\mathrm{x}_{\mathrm{t}-1} \\
\mathrm{k}_{\mathrm{t}-1}
\end{array}\right]+\left[\begin{array}{ll}
\mu & 1 \\
0 & 0
\end{array}\right]\left[\begin{array}{c}
1 \\
\mathrm{w}_{\mathrm{t}}
\end{array}\right] .
$$

The (determinate) solution, which is $x_{t}=\mu(1-a)^{-1}+w_{t}$, satisfies

$$
\left[\begin{array}{l}
x_{t} \\
k_{t}
\end{array}\right]=\left[\begin{array}{ll}
0 & a \\
0 & 0
\end{array}\right]\left[\begin{array}{l}
x_{t-1} \\
k_{t-1}
\end{array}\right]+\left[\begin{array}{ll}
\mu & 1 \\
\mu(1-a)^{-1} & 0
\end{array}\right]\left[\begin{array}{c}
1 \\
w_{t}
\end{array}\right] .
$$

The matrix denoted $F=\left[I-A_{11} \Omega\right]^{-1} A_{11}$ is then found from

$$
\begin{aligned}
& \mathrm{A}_{11} \Omega=\left[\begin{array}{ll}
0 & 0 \\
1 & 0
\end{array}\right]\left[\begin{array}{ll}
0 & \mathrm{a} \\
0 & 0
\end{array}\right]=\left[\begin{array}{ll}
0 & 0 \\
0 & \mathrm{a}
\end{array}\right] \text { and }\left[\mathrm{I}-\mathrm{A}_{11} \Omega\right]^{-1}=\left[\begin{array}{cc}
1 & 0 \\
0 & (1-\mathrm{a})^{-1}
\end{array}\right] \text { to be } \\
& \mathrm{F}=\left[\begin{array}{ll}
0 & 0 \\
(1-\mathrm{a})^{-1} & 0
\end{array}\right], \text { so its eigenvalues are } 0 \text { and } 0 . \text { Thus } \Omega^{\prime} \otimes \mathrm{F} \text { and } \mathrm{R}^{\prime} \otimes \mathrm{F} \text { also have only }
\end{aligned}
$$

zero eigenvalues, and the conditions for E-stability are met regardless of the magnitude of a.

If, by contrast, the information set in $\mathrm{t}$ does not include $\mathrm{x}_{\mathrm{t}}$, then the conditions for $\mathrm{E}$ -

\footnotetext{
${ }^{24}$ For an explicit example, see McCallum (2004).
} 
stability analogous to (23) are, as given by E\&H (2001, p. 245), that the eigenvalues of the following matrices all have real parts less than 1.0:

(27a) $\quad \mathrm{A}_{11}(\mathrm{I}+\Omega)$

(27b) $\Omega^{\prime} \otimes \mathrm{A}_{11}+\mathrm{I} \otimes \mathrm{A}_{11} \Omega$

(27c) $\quad \mathrm{R}^{\prime} \otimes \mathrm{A}_{11}+\mathrm{I} \otimes \mathrm{A}_{11} \Omega$

In the case at hand the first of these matrices equals $\left[\begin{array}{ll}0 & 0 \\ 1 & \mathrm{a}\end{array}\right]$, which has the eigenvalues 0

and a. Therefore, $\mathrm{a}<1$ is a necessary condition for E-stability, as in the univariate analysis of E\&H (2001, pp. 174-181). But under the information assumption of the present paper, that condition is not operative. Analysis for the case in which current endogenous variables are not in the information set is of considerable interest, of course, but is a major undertaking and will not be considered in the present paper. ${ }^{25}$

Some analysts might suggest that the appearance of $\mathrm{E}_{\mathrm{t}-1} \mathrm{x}_{\mathrm{t}}$ in the example's structural equation would imply that the relevant information set for learning would necessarily exclude $\mathrm{x}_{\mathrm{t}}$, but that position seems incorrect; the specification of information sets available for expectation formation in period $\mathrm{t}$ is a different matter from the specification of what period's expectations influence the determination of variables in t. The lack of any necessary connection becomes apparent if one asks, "what is the appropriate information set if the model includes (for example) both $\mathrm{E}_{\mathrm{t}-1} \mathrm{x}_{\mathrm{t}}$ and $\mathrm{E}_{\mathrm{t}} \mathrm{x}_{\mathrm{t}+1}$ ?" Evidently, either information assumption is possible. Such models are only briefly mentioned in E\&H (2001, pp. 205206) and E\&H (1999, pp. 500-501), but one example is considered more fully in Evans

\footnotetext{
${ }^{25}$ A referee has noted that the referenced $\mathrm{E} \& \mathrm{H}$ analysis assumes that $\mathrm{w}_{\mathrm{t}}$ is also absent from the information set for $t$. This is correct, and points to the desirability of considering conditions relevant for such cases in general, but does not affect the crucial point at issue here, i.e., the E-stability result for the present example under our information assumption.
} 
(1989) where it is assumed that the information set for learning does not include current values of endogenous variables. Examples of this type play a prominent role in the discussions of McCallum (1999) and Adam, Evans, and Honkapohja (2006).

\section{Conclusion}

This paper's argument begins with the presumption that learnability, which usually goes hand-in-hand with E-stability, is a necessary condition for a RE solution to be plausible. It then considers a class of linear models for which Evans and Honkapohja (2001) have derived conditions for E-stability. That class is shown to be quite broad, as it includes essentially all models of the form used by King and Watson (1998) and Klein (2000), which permits any number of lags, leads, and lags of leads. The paper's first proposition is that, if current-period information is available in the E-stability/learning process, determinacy is a sufficient condition for E-stability—a result not previously noted for any general setting. Determinacy is not a necessary condition, however; our second proposition is that there exist cases in which there is more than one stable solution yet the (unique) solution based on the decreasing-modulus ordering of the system's eigenvalues is E-stable. If in such a case the other stable solution(s) are not E-stable, then the condition of indeterminacy may not be important for practical issues. 


\section{Appendix A}

Here the objective is briefly to provide an introductory review of the concepts of E-stability and LS learnability. Let us do so within the context of a flexible univariate model studied by E\&H (2001, p. 201) and many others, which we write as

(A1) $\mathrm{y}_{\mathrm{t}}=\alpha+\mathrm{aE}_{\mathrm{t}} \mathrm{y}_{\mathrm{t}+1}+\mathrm{cy}_{\mathrm{t}-1}+\mathrm{u}_{\mathrm{t}}$,

where $u_{t}=\rho u_{t-1}+\varepsilon_{t}$ with $|\rho|<1$ and $\varepsilon_{t}$ being white noise. With this specification, the usual "fundamentals" RE solution is of the form

(A2) $\mathrm{y}_{\mathrm{t}}=\phi_{0}+\phi_{1} \mathrm{y}_{\mathrm{t}-1}+\phi_{2} \mathrm{u}_{\mathrm{t}}$,

but suppose that agents do not "initially" know the exact values of the $\phi_{\mathrm{j}}$ parameters. If at any date $t$ the agents' prevailing belief is that their values are $\phi_{0}(\mathrm{n}), \phi_{1}(\mathrm{n})$, and $\phi_{2}(\mathrm{n})-$ where $\mathrm{n}$ indexes iterations - so that the perceived law of motion (PLM) is

(A3) $\mathrm{y}_{\mathrm{t}}=\phi_{0}(\mathrm{n})+\phi_{1}(\mathrm{n}) \mathrm{y}_{\mathrm{t}-1}+\phi_{2}(\mathrm{n}) \mathrm{u}_{\mathrm{t}}$,

then the implied unbiased expectation of $\mathrm{y}_{\mathrm{t}+1}$ will be

(A4) $\phi_{0}(\mathrm{n})+\phi_{1}(\mathrm{n}) \mathrm{y}_{\mathrm{t}}+\phi_{2}(\mathrm{n}) \rho \mathrm{u}_{\mathrm{t}}$

Using this last expression in place of $\mathrm{E}_{\mathrm{t}} \mathrm{y}_{\mathrm{t}+1}$ in (A1) —which implies that we have temporarily abandoned RE—gives

(A5) $\mathrm{y}_{\mathrm{t}}=\alpha+\mathrm{a}\left[\phi_{0}(\mathrm{n})+\phi_{1}(\mathrm{n}) \mathrm{y}_{\mathrm{t}}+\phi_{2}(\mathrm{n}) \rho \mathrm{u}_{\mathrm{t}}\right]+\mathrm{cy}_{\mathrm{t}-1}+\mathrm{u}_{\mathrm{t}}$

or, rearranging,

(A6) $y_{t}=\left[1-a \phi_{1}(n)\right]^{-1}\left[\alpha+a \phi_{0}(n)+a \phi_{2}(n) \rho u_{t}+c y_{t-1}+u_{t}\right]$

as the system's actual law of motion (ALM). Now imagine a sequence of iterations from the PLM to the ALM. Writing the left-hand side of (A6) in the form (A3), that is, as $\phi_{0}(\mathrm{n}+1)+\phi_{1}(\mathrm{n}+1) \mathrm{y}_{\mathrm{t}-1}+\phi_{2}(\mathrm{n}+1) \mathrm{u}_{\mathrm{t}}$, for iteration $\mathrm{n}+1$ then implies that 
(A7a) $\phi_{0}(n+1)=\left[1-a \phi_{1}(n)\right]^{-1}\left[\alpha+a \phi_{0}(n)\right]$

(A7b) $\phi_{1}(\mathrm{n}+1)=\left[1-\mathrm{a} \phi_{1}(\mathrm{n})\right]^{-1} \mathrm{c}$

(A7c) $\phi_{2}(\mathrm{n}+1)=\left[1-\mathrm{a} \phi_{1}(\mathrm{n})\right]^{-1}\left[\mathrm{a} \phi_{2}(\mathrm{n}) \rho+1\right]$.

The issue, then, is whether iterations defined by the difference equations (A7) are such that the $\phi_{j}(n)$ converge to the $\phi_{j}$ values in an expression of form (A2) as $n \rightarrow \infty$. If they do, then that solution (A2) is said to be iteratively E-stable. Evans (1986) found that in several prominent and controversial examples the MSV solution is iteratively E-stable.

On the basis of results by Marcet and Sargent (1989), Evans (1989) and Evans and Honkapohja (1992) switched attention to E-stability without the "iterative" qualification, defined as follows. Conversion of equations (A7) to a continuous form, appropriate as the iteration interval approaches zero, ${ }^{26}$ results in

(A8a) $d \phi_{0}(n) / d n=\left[1-a \phi_{1}(n)\right]^{-1}\left[\alpha+a \phi_{0}(n)\right]-\phi_{0}(n)$

(A8b) $d \phi_{1}(n) / d n=\left[1-a \phi_{1}(n)\right]^{-1} c-\phi_{1}(n)$

(A8c) $d \phi_{2}(n) / d n=\left[1-a \phi_{1}(n)\right]^{-1}\left[a \phi_{2}(n) \rho+1\right]-\phi_{2}(n)$.

If the differential equation system (A8) is such that $\phi_{\mathrm{j}}(\mathrm{n}) \rightarrow \phi_{\mathrm{j}}$ for all $\mathrm{j}$, the solution (A2) is E-stable. ${ }^{27}$ An important feature of this continuous version of the iterative process is that it is intimately related to an adaptive learning process that is modeled as taking place in real time ${ }^{28}$ For most models of interest, that is, values of parameters analogous to the $\phi_{\mathrm{j}}$ in (A2) that are estimated by LS regressions on the basis of data from periods $\mathrm{t}-1, \mathrm{t}-2$, $\ldots, 1$ and used to form expectations in period t, will converge to the actual values in (A2)

\footnotetext{
${ }^{26}$ There is also a positive speed-of-adjustment coefficient in each of equations (8), but its magnitude is irrelevant for the convergence issue so is usually (as here) set equal to 1. See, e.g., Evans (1989, p. 299).

${ }^{27}$ Throughout the paper we are discussing weak E-stability, rather than the more demanding concept of strong E-stability. For the distinction, see E\&H (2001, pp. 41-42).

${ }^{28}$ The E-stability process is itself conceived of as taking place in notional time (meta time).
} 
as time passes if equations (A8) converge to those values and (A2) is dynamically stable (non-explosive). Also, such convergence will not occur if equations (A8) do not converge. Thus E-stability and LS learnability typically go hand in hand. This result, which is discussed extensively by Evans and Honkapohja $(1999,2001)$, is useful because it is technically much easier, in many cases, to establish E-stability than to establish LS learnability, whereas the latter concept is the more fundamental in terms of solution plausibility. 


\section{References}

Adam, K., 2003. Learning and Equilibrium Selection in a Monetary Overlapping Generations Model with Sticky Prices. Review of Economic Studies 70, 887-908.

Adam, K., G. W. Evans, and S. Honkapohja, 2006. Are Stationary Hyperinflation Paths Learnable? Journal of Economic Dynamics and Control, forthcoming.

Benhabib, J., S. Schmitt-Grohe, and M. Uribe, 2001. The Perils of Taylor Rules. Journal of Economic Theory 96, 40-69.

Bernanke, B. S., and M. Woodford, 1997. Inflation Forecasts and Monetary Policy. Journal of Money, Credit, \& Banking 24, 653-684.

Binder, M. and M. H. Pesaran, 1995. Multivariate Rational Expectations Models and Macroeconometric Modeling: A Review and Some New Results. Handbook of Applied Econometrics, edited by M. H. Pesaran and M. Wickens. Basil Blackwell Publishers. , 1997. Multivariate Linear Rational Expectations

Models: Characterization of the Nature of the Solutions and their Fully Recursive Computation. Econometric Theory 13, 877-888.

Blanchard, O. and C. M. Kahn, 1980. The Solution of Linear Difference Models Under Rational Expectations. Econometrica 48, 1305-1311.

Bullard, J. and K. Mitra, 2002. Learning About Monetary Policy Rules. Journal of Monetary Economics 49, 1105-1129.

Cochrane, J. H., 1998. A Frictionless View of U.S. Inflation. NBER Macroeconomics Annual 1998. MIT Press. 
DeCanio, S. J., 1979. Rational Expectations and Learning from Experience. Quarterly Journal of Economics 93, 47-57.

Evans, G. W., 1985. Expectational Stability and the Multiple Equilibrium Problem in Linear Rational Expectations Models. Quarterly Journal of Economics 100, 1217-1233. , 1986. Selection Criteria for Models with Non-Uniqueness. Journal of Monetary Economics 18, 147-157. , 1989. The Fragility of Sunspots and Bubbles. Journal of Monetary

Economics 23, 297-317.

Evans, G. W. and S. Honkapohja, 1992. On the Robustness of Bubbles in Linear RE Models. International Economic Review 33, 1-14. and 1991. Learning Dynamics in Handbook of

Macroeconomics, J.B. Taylor and M. Woodford, eds. North-Holland. and , 2001. Learning and Expectations in

Macroeconomics. Princeton Univ. Press. and ,2003. Expectations and the Stability Problem for

Optimal Monetary Policies. Review of Economic Studies 70, 807-824.

Evans, G. W., and R. Guesnerie, 2003. Coordination on Saddle-Path Solutions: the Eductive Viewpoint_-Linear Multivariate Models. Working Paper.

Golub, G. H, and C. F. Van Loan, 1996. Matrix Computations, 3rd ed. Johns Hopkins University Press.

King, R. G., 2000. The New IS-LM Model: Language, Logic, and Limits. Federal Reserve Bank of Richmond Economic Quarterly 86, 45-103. 
King, R. G., and M. W. Watson, 1998. The Solution of Singular Linear Difference Systems Under Rational Expectations. International Economic Review 39, 1015-1026.

Klein, P., 2000. Using the Generalized Schur Form to Solve a Multivariate Linear Rational Expectations Model. Journal of Economic Dynamics and Control 24, 1405-1423.

Kocherlakota, N. and C. Phelan, 1999. Explaining the Fiscal Theory of the Price Level. Federal Reserve Bank of Minnesota Quarterly Review 23, 14-23. Magnus, J. R., and H. Neudecker, 1988. Matrix Differential Calculus with Applications In Statistics and Econometrics. John Wiley and Sons.

McCallum, B. T., 1983. On Non-Uniqueness in Rational Expectations Models: An Attempt at Perspective. Journal of Monetary Economics 11, 139-168. , 1998. Solutions to Linear Rational Expectations Models: A

Compact Exposition. Economics Letters 61, 143-147. , 1999. Role of the Minimal State Variable Criterion in Rational

Expectations Models in International Tax and Public Finance 6, 621-639. Also in International Finance and Financial Crises: Essays in Honor of Robert P. Flood, Jr., P. Isard, A. Razin, and A.K. Rose, eds. Kluwer Academic Publishing. , 2001. Indeterminacy, Bubbles, and the Fiscal Theory of the Price Level. Journal of Monetary Economics 47, 19-30. , 2004. On the Relationship Between Determinate and MSV Solutions in Linear RE Models. Economics Letters 84, 55-60. 
Sims, C. A., 1994. A Simple Model for the Study of the Determination of the Price Level and the Interaction of Monetary and Fiscal Policy. Economic Theory 4, 381-399.

Uhlig, H., 1999. A Toolkit for Analyzing Nonlinear Dynamic Stochastic Models Easily. In Computational Methods for the Study of Dynamic Economies, R. Marimon and A. Scott, eds. Oxford University Press.

Woodford, M., 1994. Nonstandard Indicators for Monetary Policy: Can Their Usefulness Be Judged From Forecasting Regressions? In Monetary Policy, N.G. Mankiw, ed. University of Chicago Press for NBER. , 1995. Price-Level Determinacy Without Control of a Monetary

Aggregate. Carnegie-Rochester Conference Series on Public Policy 43, 1-46. , 2003. Interest and Prices, Princeton University Press. 